\title{
The International Journal of Medical Students, a Platform for Medical Student Research Worldwide
}

IJMS website www.ijms.info

Editorial Board of IJMS http://ijms.info/journal/ editorial-board/
It is our great honor to present to you the first issue of the International Journal of Medical Students, IJMS, a peer-reviewed open-access journal, created to share the scientific production and experiences of medical students worldwide.

Research has been historically recognized as the driving force of medical progress. As evidence-based medicine becomes progressively an integral part of clinical practice, trends in medical education demand healthcare providers to be versed in the scientific method, as well as become active contributors to the generation of knowledge. The inherent social responsibility of clinical practice implies that gaps in knowledge identified in providing care can only be judiciously addressed through medical research. As a result, there has been an increasing interest in educators and medical students to become involved in research opportunities at earlier stages of their education as a way to foster scientific initiative concurrent to clinical training. Consequently governments, academic medical associations such as the Association of American Medical Colleges, major academic institutions, and medical student associations have recognized the importance of promoting the involvement of medical students in research.

The increased scientific production of medical students has led to the development of meetings especially designed to facilitate the presentation of their work. To a lesser extent, students can often publish their findings in the medical literature, but existing medical student journals currently represent local universities, regional associations, or are housed under recognized journals as spaces to share only opinions, experiences and advice. Thus, the IJMS emerges to give a voice to those medical students who actively participate in research and contribute to the progress of medicine and the service of their communities by creating the first international scientific platform of the highest scientific quality for the publication of their work.
The IJMS has its origins in the XXIV International Scientific Congress (XXIV Congreso Cientifico Internacional) of the Latin American Federation of Medical Students' Associations (FELSOCEM) in 2009. Initial strategies were discussed among medical students involved in the Peruvian Medical Students' Scientific Society (SOCIMEP), the International Federation of Medical Students' Associations - Peru (IFMSA-Peru), the Association of Scientific Societies of Medical Students from Colombia (ASCEMCOL), the European Medical Students' Association (EMSA), and the International Federation of Medical Students' Association (IFMSA). We are proud that this project, initially started in Latin America, has now been embraced by students around the world.

Our team is led by the Executive Committee, composed of the Editor in Chief, Américo Peña-Oscuvilca (SOCIMEP), Associate Editor, Juliana Bonilla-Velez (ASCEMCOL), and Scientific Editor, llyas Sahin (EMSA). They form the Editorial Board in conjunction with our Mentors, renowned physician scientists from the most distinguished institutions; Senior Editors or Advisors, who are physicians starting their careers as investigators; and Junior Editors, who are medical students with experience in research and the publication process. Furthermore, the Support Committee of Public Relations and Communications includes the Director, Whitney S. Cordoba-Grueso, and Ambassadors of IJMS, who are medical students from different regions of the world who promote the journal to medical students and physicians worldwide.

Our primary goal is to be an international divulgation tool for medical students using the highest standards of scientific publication. The Journal is licensed under a Creative Commons Attribution 3.0 License and its editorial policy is based on the Uniform Requirements for Manuscripts Submitted to Biomedical Journals published by the International Committee of Medical Journal Editors. The IJMS receives manuscripts where there has been participation of at least

\footnotetext{
${ }^{1}$ Executive Committee, International Journal of Medical Students.

${ }^{2}$ Massachusetts Eye and Ear Infirmary, Harvard Medical School, Boston, MA, USA

${ }^{3}$ Universidad del Valle, Cali, Colombia.

${ }^{4}$ School of Medicine, Jose Faustino Sanchez Carrion University, Huacho, Peru.

${ }^{5}$ Dana Farber Cancer Institute, Harvard Medical School, Boston, MA, USA.

${ }^{6}$ Hacettepe University, Ankara, Turkey.

${ }^{7}$ Mayo Clinic, Rochester, MN, USA.

Correspondence

Américo Peña-Oscuvilca, M.D.

Address: Mercedes Indacochea 609, Ave, University City, Huacho, Peru.

E.mail: editor.in.chief@ijms.info.
} 
one medical student and presents information relevant to medical education and medicine, giving priority to scientific accuracy, novelty and relevance to the medical student and medical community as a whole. We welcome submissions of Original Articles, Short Communications, Case Reports, Reviews and Letters to the Editor. We also have a special section where students may share interviews with leaders in medicine or other Experiences.

In IJMS we strive to promote student training in research and editorial processes through several strategies. For authors, our tutoring system provides feedback on how to improve their manuscript to potentially achieve publication. For junior editors, we provide an exceptional experience to develop skills on the critical evaluation of manuscripts under the guidance of expert editors, as well as on the internal functioning of a peer-reviewed journal. Finally, for Ambassadors it serves as an opportunity to participate in research-oriented initiatives and to share the culture of investigation with their peers, all within an environment of international collaboration and cultural exchange.

As proof of the importance of this initiative among medical students, several national and regional student-led organizations have become Partners of IJMS, recognizing IJMS as their official publication and providing their institutional support. Our Partners include ASCEMCOL (Colombia); the Annual International Medical Students Meeting (AIMS Meeting, Portugal); the Bio-Medical Students' Research Initiatives (BMSRI, India); the Medical-Academic Congress of Brazilian Northeast and Medical-Academic Congress of Piauí (COMAPI, Brazil); the Georgian Young Medics' Union (GYMU, Ceorgia); the International Student Medical Congress in Kosice (ISMCK, Slovak Republic); and the Young European Scientist Meeting (YES MEETING, Portugal, Europe); and this list is continually expanding.

We are immensely proud to have assembled such a rich and experienced support system that continually helps us in our mission of truly becoming the pioneers of medical student publications, and that bring together medical students and physicians from 31 different countries around the globe. We would like to thank very specially Dr. Christian A. López-Castillo, Ahmad Adi, Dr. Jorge E. Gómez-Marín and Dr. Alfonso J. Rodríguez-Morales for their significant guidance and support in setting up this project as well as our Reviewers and Advisors for believing in this initiative and supporting it with their experience and knowledge.
We are grateful for their contributions in the formation of the future physician scientists of the world.

Without further ado, we present to you the IJMS, hoping this will become a defining moment in the history of medical student research. 